\title{
CD44 engagement enhances acute myeloid leukemia cell adhesion to the bone marrow microenvironment by increasing VLA-4 avidity
}

Haematologica 2021

Volume 106(8):2102-2113

\section{Correspondence:}

TANJA N. HARTMANN

tanjanhartmann@gmail.com

Received: July 12, 2019.

Accepted: June 26, 2020.

Pre-published: July 2, 2020.

https://doi.org/10.3324/haematol.2019.231944

(C)2021 Ferrata Storti Foundation

Material published in Haematologica is covered by copyright. All rights are reserved to the Ferrata Storti Foundation. Use of published material is allowed under the following terms and conditions:

https://creativecommons.org//icenses/by-nc/4.0/legalcode. Copies of published material are allowed for personal or internal use. Sharing published material for non-commercial purposes is subject to the following conditions:

https://creativecommons.org/licenses/by-nc/4.0/legalcode, sect. 3. Reproducing and sharing published material for commercial purposes is not allowed without permission in writing from the publisher.

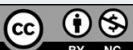

Julia C. Gutjahr,,$^{1,2^{\star}}$ Elisabeth Bayer, ${ }^{1 \star}$ Xiaobing Yu, ${ }^{3}$ Julia M. Laufer ${ }^{4}$, Jan P. Höpner, ${ }^{1}$ Suzana Tesanovic, ${ }^{5}$ Andrea Härzschel, ${ }^{6}$ Georg Auer, ${ }^{1}$ Tanja Rieß, ${ }^{1}$ Astrid Salmhofer, ${ }^{1}$ Eva Szenes, ${ }^{1}$ Theresa Haslauer, ${ }^{1}$ Valerie Durand-Onayli, ${ }^{1}$ Andrea Ramspacher, ${ }^{5}$ Sandra P. Pennisi, ${ }^{6}$ Marc Artinger, ${ }^{4}$ Nadja Zaborsky, ${ }^{1}$ Alexandre Chigaev, ${ }^{7}$ Fritz Aberger, ${ }^{5}$ Daniel Neureiter, ${ }^{8}$ Lisa Pleyer, ${ }^{1}$ Daniel F. Legler, ${ }^{4,9}$ Veronique Orian-Rousseau, ${ }^{3}$ Richard Greil ${ }^{1}$ and Tanja N. Hartmann ${ }^{1,6}$

${ }^{1}$ Department of Internal Medicine III with Hematology, Medical Oncology, Hemostaseology, Infectiology and Rheumatology, Oncologic Center, Salzburg Cancer Research Institute - Laboratory for Immunological and Molecular Cancer Research (SCRI-LIMCR), Paracelsus Medical University, Cancer Cluster Salzburg, Salzburg, Austria; ${ }^{2}$ Centre for Microvascular Research, William Harvey Research Institute, Barts and The London School of Medicine and Dentistry, Queen Mary University of London, London, UK; ${ }^{3}$ Karlsruhe Institute of Technology, Institute of Toxicology and Genetics, Karlsruhe, Germany; ${ }^{4}$ Biotechnology Institute Thurgau (BITg) at the University of Konstanz, Kreuzlingen, Switzerland; ${ }^{5}$ Department Biosciences, Paris-Lodron University of Salzburg, Cancer Cluster Salzburg, Salzburg, Austria; ${ }^{6}$ Department of Internal Medicine I, Medical Center and Faculty of Medicine, University of Freiburg, Freiburg, Germany; ${ }^{7}$ Department of Pathology and Cancer Center, University of New Mexico, Albuquerque, NM, USA; ${ }^{8}$ Institute of Pathology, Paracelsus Medical University Salzburg, Salzburg, Austria and ${ }^{9}$ Theodor Kocher Institute, University of Bern, Bern, Switzerland

*JCG and EB contributed equally as co-first authors.

\section{ABSTRACT}

dhesive properties of leukemia cells shape the degree of organ infiltration and the extent of leukocytosis. CD44 and the integrin VLA-4, a CD49d/CD29 heterodimer, are important factors in progenitor cell adhesion in bone marrow. Here, we report their cooperation in acute myeloid leukemia (AML) by a novel non-classical CD44-mediated way of inside-out VLA-4 activation. In primary AML bone marrow samples from patients and the OCI-AML3 cell line, CD44 engagement by hyaluronan induced inside-out activation of VLA-4 resulting in enhanced leukemia cell adhesion on VCAM-1. This was independent of VLA-4 affinity regulation but based on ligand-induced integrin clustering on the cell surface. CD44-induced VLA-4 activation could be inhibited by the Src family kinase inhibitor PP2 and the multikinase inhibitor midostaurin. As a further consequence, the increased adhesion on VCAM-1 allowed AML cells to bind stromal cells strongly. Thereby, the VLA-4/VCAM-1 interaction promoted activation of Akt, MAPK, NF- $\kappa B$ and $\mathrm{mTOR}$ signaling and decreased AML cell apoptosis. Collectively, our investigations provide a mechanistic description of an unusual CD44 function in regulating VLA-4 avidity in AML, enhancing AML cell retention in the supportive bone marrow microenvironment.

\section{Introduction}

Acute myeloid leukemia (AML) is an aggressive and difficult-to-treat hematologic malignancy, characterized by the accumulation of immature myeloid blasts. Within the bone marrow (BM), AML cells interact and communicate with stromal and immune cells and reprogram mesenchymal stromal cells to selectively support leukemic cells, while simultaneously suppressing normal hematopoiesis. ${ }^{1}$ These microenvironmental interactions contribute to protect leukemic stem cells from chemotherapeutic drugs, thus allowing residual disease after therapy, ultimately causing relapses. ${ }^{1} \mathrm{~A}$ better understanding of the adhesive mechanisms that facilitate 
the interactions between AML cells and the supportive microenvironment may pave the way for novel combination therapies antagonizing residual disease.

The glycoprotein CD44 functions by binding to its major ligand hyaluronic acid (HA), which is expressed by BM stromal cells and endothelial cells. ${ }^{2}$ In AML, targeting CD44 reduced leukemic repopulation in serial transplantations by eradication of leukemic stem cells. ${ }^{3}$

A second key orchestrator of leukemic cell-BM microenvironment interactions is the integrin VLA-4, a CD49d/CD29 heterodimer. The binding of VLA-4 to its ligand VCAM-1 is strengthened by inside-out signaling. This means that external stimuli mediate intracellular signaling triggered by other cell surface receptors, resulting in a change of either the avidity or the affinity of the integrin for its ligands. ${ }^{4}$ Avidity changes occur due to cluster formation of the integrin, whereas affinity is increased by conformational changes. ${ }^{5}$ Cooperativity of CD44 and VLA-4 has previously been suggested, but little is known about the mechanism. ${ }^{6-8}$ To elucidate the mechanistic crosstalk between the two key homing factors, CD44 and VLA-4, to the BM in AML cell lines and primary AML cells, we used adoptive transplantations as well as static and shear flow adhesion assays in combination with immunofluorescence microscopy approaches. We uncovered a novel HA/CD44induced inside-out activation of the integrin VLA-4. This activation leads to increased avidity due to VLA-4 clusters but no alterations in affinity between VLA-4 and its ligand VCAM-1. This elevated adhesion is important for AML cell retention in the stromal niche.

\section{Methods}

\section{Study approvals and processing of patients' samples}

Following written informed consent, BM aspirates from patients with newly diagnosed AML were collected at the Third Medical Department, Paracelsus Medical University Salzburg, Austria (Salzburg ethics committee approval number: 415E/2009/2-2016). Normal CD34+ progenitor cells from patients with myeloma or non-Hodgkin lymphoma who underwent hematopoietic stem/progenitor cell mobilization were used as non-myeloid controls (Salzburg ethics committee approval number: 415-E/1177/8-2010). Mononuclear cells were isolated using density gradient centrifugation and the viable cells were frozen until further usage. The patients' characteristics are shown in Online Supplementary Table S1.

The approval number for the animal experiments is BMWF66.012/0032-WF/V/3b/2017.

\section{Adoptive transfers}

For blocking experiments, primary AML cells or OCI-AML3 cells were pretreated with $\alpha \mathrm{CD} 44 \mathrm{Fab}$ fragments (clone 515, 5 $\mu \mathrm{g} / \mathrm{mL}$ ) or $\alpha \mathrm{CD} 49 \mathrm{~d}$ (clone HP2/1, $5 \mu \mathrm{g} / \mathrm{mL}$ ) antibodies for $15 \mathrm{~min}$ at $37^{\circ} \mathrm{C}$, where indicated. The specificity of the blockade was confirmed by isotype control experiments in representative experiments. For homing versus engraftment assays ( $3 \mathrm{~h}$ and 3 days), cells were stained using the CellTrace ${ }^{\mathrm{TM}}$ Violet Cell Proliferation Kit (Thermo Fisher). Cells $\left(0.3-1.3 \times 10^{\circ}\right)$ were injected intravenously into NOD scid gamma (NSG) mice. After 3 h or 3 days, the mice were sacrificed, and the number of human cells that had homed to $\mathrm{BM}$, spleen and peripheral blood was determined using $\alpha \mathrm{CD} 44$ (clone J.173)- and $\alpha \mathrm{CD} 49 \mathrm{~d}$ (clone 9F10)-specific antibodies. Homing rate was calculated as the number of CD44 and CD49d double-positive cells divided by the number of total measured cells divided by the number of injected AML cells., ${ }^{9,10}$ Proliferation after 3 days was determined on the basis of CellTrace ${ }^{\mathrm{TM}}$ dye dilution rates..$^{10}$ For long-term engraftment (28 days) shCont or shCD49d OCI-AML3 cells were injected intravenously into NSGS mice. After 28 days, the mice were sacrificed, and the number of human CD15 and CD45 double-positive cells per million measured BM cells, spleen cells or per microliter of blood was determined.

\section{Clustering assay}

VLA-4 clustering assays were performed as described elsewhere, ${ }^{11}$ using $7.5 \mu \mathrm{g} / \mathrm{mL}$ VCAM-1/Fc. AML cells were pretreated for $10 \mathrm{~min}$ with $10 \mu \mathrm{g} / \mathrm{mL}$ HA, 60 min with $1 \mu \mathrm{M}$ midostaurin, 30 min with $10 \mu \mathrm{M}$ PP2 and $30 \mathrm{~min}$ with $10 \mu \mathrm{M}$ cobimetinib (APExBIO, Houston, USA), where indicated. Cells were allowed to adhere for $30 \mathrm{~min}$ at $37^{\circ} \mathrm{C}$ before fixation with $4 \%$ paraformaldehyde. Slides were stained with $\alpha \mathrm{CD} 49 \mathrm{~d}$ (clone AHP1225), aCD29 (clone 12G10) primary antibodies or isotype control (not shown) followed by a secondary antibody. For CD49d cluster analysis of normal progenitor cells from patients with non-myeloid malignancies, cells were additionally stained with $\alpha$ CD34 antibody (clone OBEND-10). For quantification, high-resolution images were acquired on a Leica TCS SP5 II laserscanning microscope using a 63x/1.4-NA oil-immersion objective (Leica, Wetzlar, Germany). The number of clusters was analyzed using ImageJ software by particle analysis setting the size of the particle at $>2$ pixels. ${ }^{12}$

\section{Stroma binding}

Falcon culture slides were left either uncoated or coated with 20 $\mu \mathrm{g} / \mathrm{mL}$ fibronectin for $1 \mathrm{~h}$ at $37^{\circ} \mathrm{C}$ and then $70,000 \mathrm{M} 2$ stromal cells were seeded and cultured overnight. Primary AML $\left(1 \times 10^{\circ}\right.$ cells) or OCI-AML3 cells $\left(0.5 \times 10^{6}\right.$ cells $)$ were seeded on M2 stromal cells and co-cultured for $30 \mathrm{~min}$ at $37^{\circ} \mathrm{C}$. Cells were washed, fixed with $4 \%$ paraformaldehyde, and stained using DAPI Antifade Reagent. Images were taken with an Olympus IX81 microscope (UPLSAPO 20xO/0.85 objective). Numbers of cells were determined in 12 pictures for each treatment with ImageJ software.

Additional experimental procedures are described in the Online Supplementary Methods.

\section{Results}

\section{CD44 reflects and mediates leukemic infiltration of bone marrow}

We measured CD44 and CD49d surface expression of BM-derived primary AML patients' samples and the AML cell line OCI-AML3 by flow cytometry. All AML patientderived blasts, identified via CD45/side scatter gating, ${ }^{13}$ and OCI-AML3 cells, expressed CD44 and CD49d (Figure 1A). We also screened various other AML cell lines, which cover most of the AML subtypes, i.e., MV4-11, KG-1a, HL-60, MOLM-13 and MOLM-14, and found a similar expression pattern (Online Supplementary Figure S1A).

We next determined the in vivo contribution of CD44 and CD49d to homing of AML cells by performing short-term adoptive transfer experiments of primary human AML cells as well as OCI-AML3 cells in immunodeficient NSG mice. In five independent experiments, total mononuclear cells from BM aspirates of five different AML patients (2 with wild-type FLT3, 3 with FLT3-ITD mutations) with a blast content of over $75 \%$ were either left untreated or treated with $\alpha \mathrm{CD} 44 \mathrm{Fab}$ fragment (clone 515) or $\alpha \mathrm{CD} 49 \mathrm{~d}$ antibody 


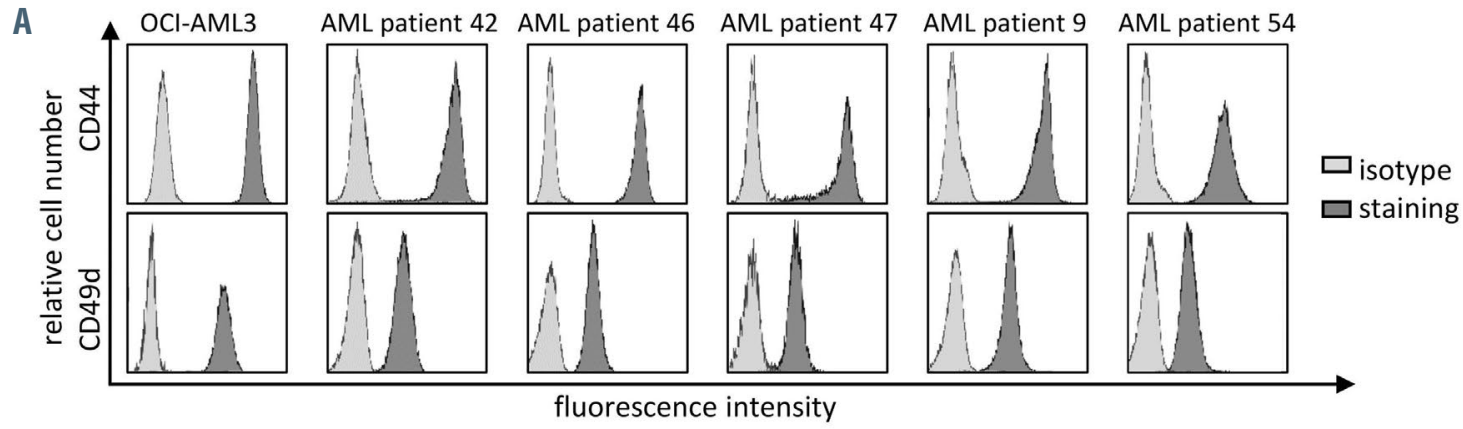

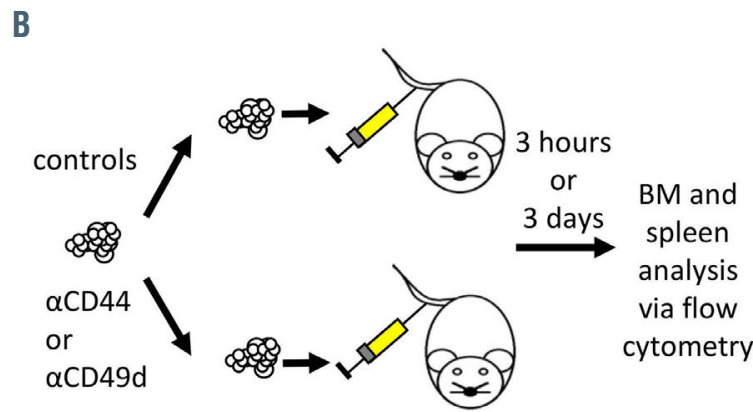

Cii
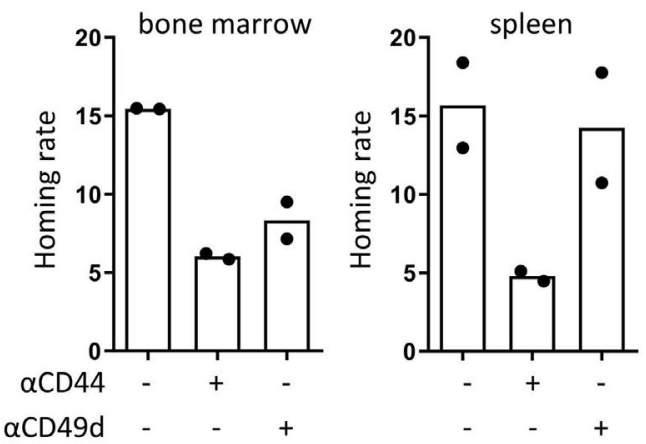

Ci

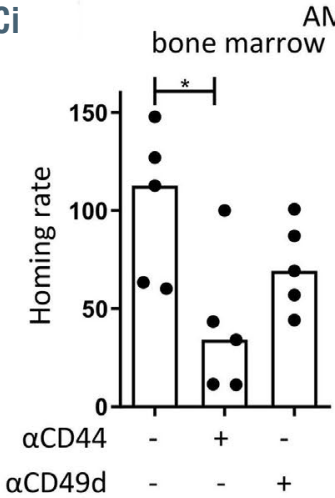

AML patients

spleen

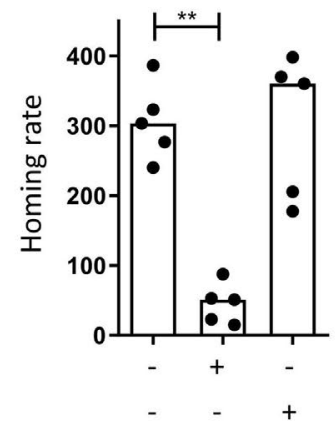

Di

Dii

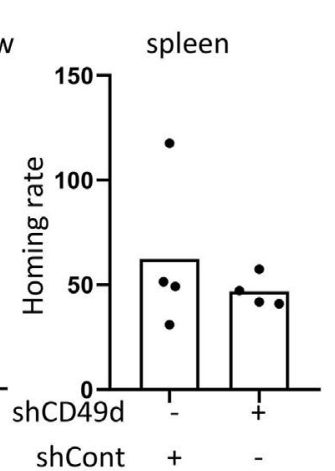

E

$\square 3$ hours

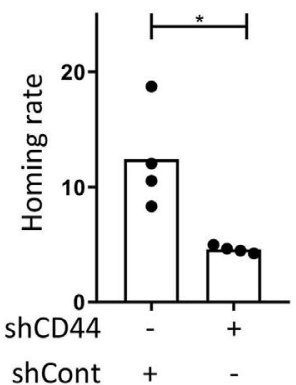

spleen
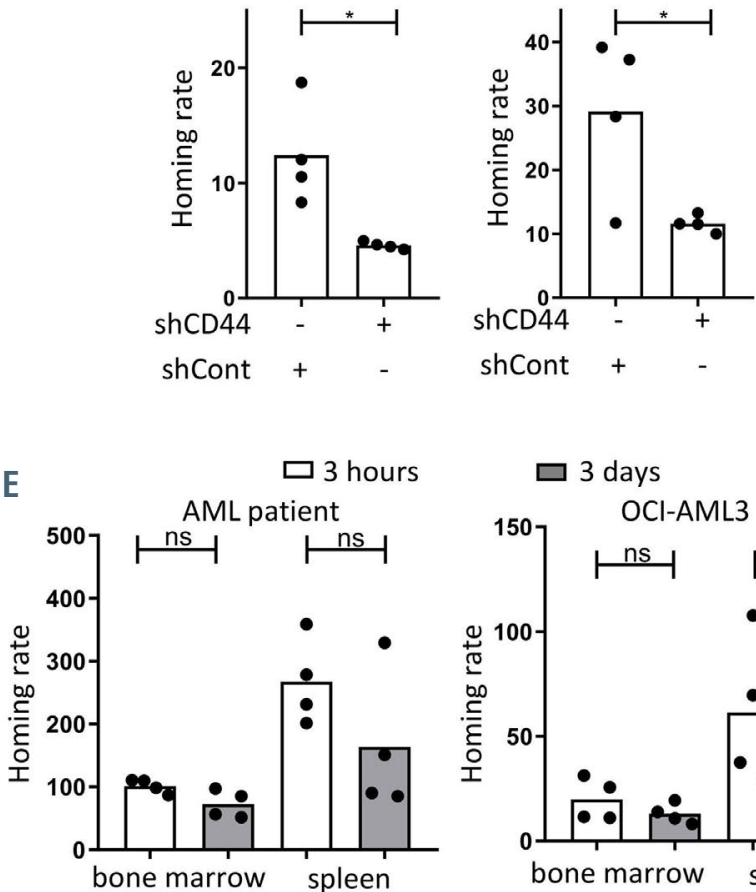

$\square 3$ days

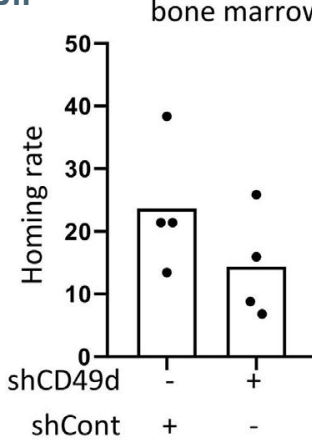

shCont

Figure 1. CD44 and CD49d are both expressed on acute myeloid leukemia cells; CD44 has a predominant role in homing. (A) Representative histograms of CD44 and CD49d surface expression of primary acute myeloid leukemia (AML) cells and the AML cell line OCl-AML3. (B) Mononuclear cells from bone marrow (BM) aspirates of AML patients pretreated or not with $\alpha \mathrm{CD} 44$ antibody clone $515(\alpha \mathrm{CD} 44)$ or $\alpha \mathrm{CD} 49 \mathrm{~d}$ clone HP2/1 ( $\alpha \mathrm{CD} 49 \mathrm{~d})$ were injected into the tail veins of NSG mice. After $3 \mathrm{~h}$ the number of AML cells that had homed to BM and spleen of the recipients was determined by flow cytometry using human-specific $\alpha C D 44$ and $\alpha C D 49 \mathrm{~d}$ antibodies. The homing rate was defined as the number of measured leukemic cells per $10^{6}$ measured cells per $10^{6}$ injected cells. (Ci) Homing rate to BM and spleen $3 \mathrm{~h}$ after injection was measured in five independent experiments using samples from five different AML patients. In each experiment, technical duplicates were performed and they were averaged for the analysis. (Cii) Homing rate to BM and spleen was measured $3 \mathrm{~h}$ after injection of OCI-AML3 ( $\mathrm{n}=2$ ). (Di $+\mathrm{ii}$ ) Homing rate to BM and spleen was measured $3 \mathrm{~h}$ after injection of OCl-AML3 cells transduced with shCD44 or shCD49d or control shRNA (shCont) ( $\mathrm{n}=4$, unpaired $t$-test). (E) Mononuclear cells from the BM aspirate of one AML patient and OCl-AML3 cells were injected into the tail veins of NSG mice. After $3 \mathrm{~h}$ and 3 days the number of AML cells that had homed or engrafted to BM and spleen of the recipient mice was determined by flow cytometry using human-specific $\alpha C D 44$ and $\alpha C D 49 d$ antibodies ( $\mathrm{n}=4$, unpaired $t$-test). $* P<0.05 ; * * P<0.01$; ns: not significant. 
(clone HP2/1) and intravenously injected into NSG mice. Mice were sacrificed after $3 \mathrm{~h}$ (short-term homing, allowing leukemia cell entry into organs but no proliferation), and transplanted cells were flow cytometrically identified in the spleen and BM by human-specific antibodies (Figure 1B). Cells that had been treated with the blocking $\alpha$ CD44 Fab fragment had a lower capacity to home to BM within $3 \mathrm{~h}$ compared to untreated cells. The homing of primary human AML cells to the spleen was strongly diminished upon CD44 blockade. In contrast, $\alpha \mathrm{CD} 49 \mathrm{~d}$ antibody treatment only slightly reduced BM homing of AML blasts and had no effect on their spleen homing (Figure 1Ci). In four of the five homing experiments we combined $\alpha C D 44 / \alpha C D 49 d$ treatment, but additional CD49d blockade did not further increase the inhibitory effect above the level achieved by treatment with $\alpha \mathrm{CD} 44$ alone (Online Supplementary Figure S1B). Comparable effects were observed when using OCI-AML3 cells (Figure 1Cii). The significantly reduced recovery of $\alpha C D 44$-treated cells was not due to toxicity of the antibody, as in vitro treatment for $3 \mathrm{~h}$ had no effect on cell viability (Online Supplementary Figure S2A). Neither the functional inhibition of CD44 nor the inhibition of CD49d affected the general CD44 and CD49d expression of the cells (Online Supplementary Figure S2B). Anti-CD44 antibody treatment did not affect CD44/E-selectin-mediated cell arrest (Online Supplementary Figure S2C). We genetically confirmed the contribution of CD44 to homing by CD44 knockdown in OCI-AML3 cells (Online Supplementary Figure S2Dii), observing a significant reduction in homing of CD44 ${ }^{\text {low }}$ cells (Figure $1 \mathrm{Di}$ ). These cells also showed reduced rolling on HA substrates under shear flow (Online Supplementary Figure S2Di). CD49d knockdown, which was confirmed via quantitative polymerase chain reaction (PCR), did slightly reduce homing and arrests of CD49d knockdown OCI-AML3 on VCAM-1 substrate were diminished (Figure 1Dii, Online Supplementary Figure S2Ei+ii). Concurrent analysis 3 days after transplantation allowed us to investigate not only homing but also early engraftment, which includes the first proliferation events. ${ }^{14}$ We noted equal numbers of primary AML cells and OCI-AML3 cells at $3 \mathrm{~h}$ and 3 days in BM while leukemic recovery in spleen was diminished after 3 days (Figure 1E). In concordance, recovered AML cells had undergone more cell divisions in BM than in spleen at this time (Online Supplementary Figure S2Fi+ii), indicating that the $\mathrm{BM}$ rather than the spleen microenvironment provides supportive signals for leukemic engraftment. Furthermore, when NSGS mice were engrafted with human AML cells and afterwards treated with an aCD44 antibody, the AML pool shifted from BM to spleen 1 day after treatment, suggesting that CD44 is a BM retention factor (Online Supplementary Figure S2G). In summary, we found that CD44 plays a key role in homing of AML cells to murine $\mathrm{BM}$ and spleen, with the BM providing a favorable environment for early engraftment of AML.

\section{An interaction between hyaluronic acid and CD44 triggers inside-out activation of VLA-4 in acute myeloid leukemia}

To dissect the AML homing process in a mechanistic manner, we used in vitro flow chamber assays, as described elsewhere..$^{15}$ These assays allowed us to study the individual and combined interactions of CD44 and VLA-4 expressed on AML cells with the respective ligands HA and VCAM-1. First, we perfused OCI-AML3 cells over an immobilized HA substrate under shear stress. We found that the cells had a strong capacity to tether to and roll on this substrate: this capacity was completely abolished upon
A

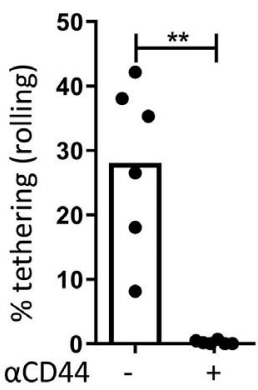

Bì

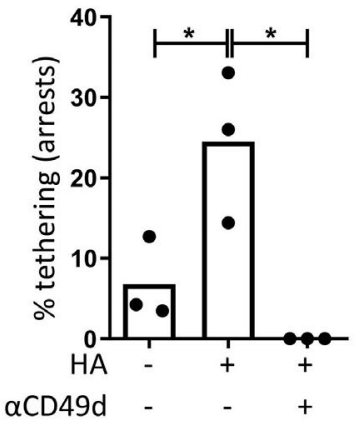

C

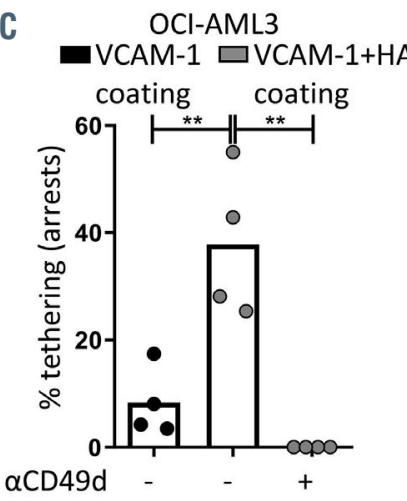

D

OCI-AML3

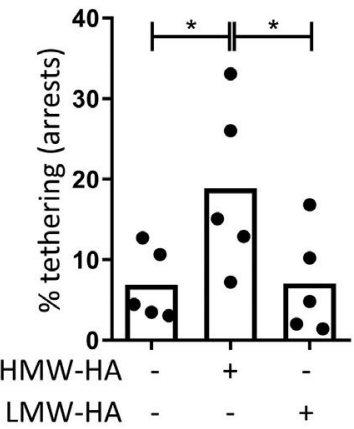

Bii

AML patients

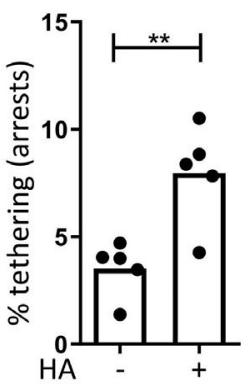

E

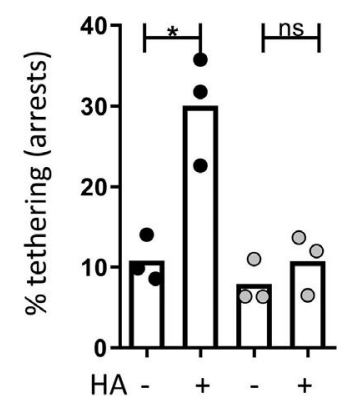

Figure 2. Hyaluronic acid treatment increases acute myeloid leukemia cell arrests on VCAM-1 under shear flow. (A) OCI-AML3 cells were perfused over hyaluronic acid (HA) Where indicated, cells were pretreated with blocking $\alpha \mathrm{CD} 44$ antibody (clone 515). (B) OCI-AML3 (i) or primary acute myeloid leukemia (AML) cells from five different patients (ii) were perfused over VCAM-1. Where indicated, cells were pretreated with soluble HA or $\alpha \mathrm{CD} 49 \mathrm{~d}$ antibody (clone HP2/1) (abrogating VLA-4 mediated interactions). (C) OCI-AML3 cells were perfused over a VCAM- 1 or VCAM-1/HA substrate upon pretreatment with aCD49d antibody (clone $\mathrm{HP} 2 / 1$ ), where indicated. (D) OClAML3 cells were perfused over VCAM-1. Where indicated, cells were pretreated with low molecular weight HA (LMW-HA) or high molecular weight HA (HMW-HA). (E) OCI-AML3 cells transduced with shCD44 or control shRNA were perfused over VCAM1; cells were pretreated with soluble $\mathrm{HA}$, where indicated. Categories of interaction (tethers) are expressed as frequencies of cells in direct contact with the substrate. Two groups were compared with a paired $t$-test, three groups were compared with one-way analysis of variance with multiple comparisons. $* P<0.05$ $\star \star P<0.01$; ns: not significant. 
treatment with $\alpha \mathrm{CD} 44$ blocking antibody (clone 515) (Figure 2A). We further confirmed this HA-binding capacity by flow cytometry using fluorescein-labeled HA (HA-FITC) (Online Supplementary Figure S3A). Next, we tested whether AML cells were capable of tethering to the VLA-4 ligand VCAM-1 under shear flow conditions. Unstimulated OCIAML3 and primary AML cells from five different patients bound immobilized VCAM-1 at low adhesive strength, which was evident by the low frequency of firm adhesion on this substrate (Figure 2Bi+ii). Treatment with a blocking $\alpha C D 49 d$ antibody abrogated all interactions of the OCIAML3 and primary cells with the immobilized VCAM-1, confirming the VLA-4 dependency of this process (Figure $2 \mathrm{Bi}$, Online Supplementary Figure S3B). Notably, pre-treating AML cells with the CD44 ligand HA and then perfusing the cells over a VCAM-1 substrate increased adhesion, without changing CD44 or CD49d surface expression (Figure 2Bi+ii, Online Supplementary Figure S3C), which suggests HA/CD44-induced inside-out VLA-4 activation. Co-immobilization of both ligands HA and VCAM-1 resulted in strong CD49d-dependent adhesive capacity of the leukemia cells, suggesting inside-out activation rather than mere additive effects in adhesion (Figure 2C). CD44-mediated inside-out signaling is well known to vary depending on the molecular weight of the HA trigger. ${ }^{16}$ Indeed, CD44induced VLA-4 activation was only achieved by high molecular weight HA, but not by low molecular weight HA (Figure 2D). Using shCD44-transduced OCI-AML3 cells confirmed that the increased VLA-4/VCAM-1 binding upon $\mathrm{HA}$ treatment is CD44-dependent (Figure 2E). These data indicated an unusual integrin activation, different from the well-described, classical CXCL12/CXCR4-induced VLA-4 activation, ${ }^{17}$ which led us to investigate the nature of this molecular crosstalk .

\section{Hyaluronic acid-induced inside-out signaling to VLA-4 results in CD49d cluster formation but not in VLA-4 affinity modulation}

VLA-4-dependent adhesion is controlled by either affinity changes, gained by several conformational states of the integrin ${ }^{18}$ or avidity changes due to clustering of the molecule on the cell surface ${ }^{19}$ (Online Supplementary Figure S4A). To investigate the alterations in VLA-4 conformational states upon HA treatment, we used the $\alpha \mathrm{CD} 29$ antibody (clone HUTS-21) that binds solely to the ligand-occupied state of VLA-4. ${ }^{20}$ To mimic VLA-4 ligand binding, we used a probe containing the conserved Leu-Asp-Val (LDV) sequence, specific for the VLA-4 binding site. Manganese was used as a positive control as it induces the maximal extent of VLA-4 activation, which is not achieved under physiological conditions. ${ }^{20}$ Surprisingly, OCI-AML3 cells expressed VLA-4 in an inactive conformation irrespectively of whether the cells were treated with HA or not and bound its ligand with comparable affinity (Online Supplementary Figure $S 4 B) .{ }^{15,20}$ This unexpected finding prompted us to elucidate whether the HA-induced AML cell arrests on the substrate are based on increased avidity rather than affinity of VLA-4 to VCAM-1. We performed immunofluorescence microscopy and found increased CD49d cluster formation on AML cells upon treatment with HA. This was quantified by counting the number of the clusters on the individual OCI-AML3 and patient AML cells ( 1 representative of 6 patients shown) (Figure $3 \mathrm{Ai}+\mathrm{ii}$ ). The mean number of clusters per cell was compared between untreated and HA-treated cells from all six patients (Figure 3Aiii). HA treatment also induced clustering of the VLA-4 $\beta$ subunit CD29 (Online Supplementary Figure S4C). Pretreatment with blocking $\alpha \mathrm{CD} 44$ (clone 515) inhibited cluster formation on OCI-AML3 as well as primary AML cells (Figure 3B). Using CD44 knockdown and control transduced OCI-AML3 cells, we confirmed that HAinduced CD49d clustering only occurred in cells that expressed CD44 (Figure 3C). This cluster formation translated into enhanced adhesive capacity, as we confirmed in an additional static cell adhesion assay, using an alternative colorimetric method for cell counting (Online Supplementary Figure $S 4 D$ ). We also performed an avidity-detecting shear flow assay, as described by Alon et al., ${ }^{21}$ by perfusing OCIAML3 cells and primary cells over an aCD49d (clone HP2/1) substrate, further confirming our observations (Figure 3D, Online Supplementary Figure S4E). To get an insight into the lateral organization of the VLA-4 clusters on the membrane, we used methyl-beta-cyclodextrin $(\mathrm{MBcD})$, which interferes with lipid structures. Although $M B c D$ did not significantly reduce the number of HA-induced VLA-4 clusters, it abrogated their function to support cell tethering to VCAM-1 (Online Supplementary Figure S4F).

Next, we studied whether CD44-mediated inside-out activation is a general mechanism that also occurs in nontransformed progenitor cells. Using $\mathrm{CD} 34^{+}$cells from four different patients harboring a non-myeloid, i.e. lymphoid malignancy occurring at later differentiation states (nonHodgkin-lymphoma [ $\mathrm{n}=3]$ and multiple myeloma [ $\mathrm{n}=1]$ ), we did not find HA-induced CD49d clustering, suggesting that induced cluster formation is a specific feature of transformed myeloid progenitor cells (Figure 3E).

Transformed myeloid progenitors may differ in their CD44variant (CD44v) composition, with an impact on the clinical outcome of AML patients. ${ }^{22}$ We have analyzed the CD44v composition of several cell lines as well as primary AML samples and normal CD34+ cells by reverse transcription PCR and found differences in the length of CD44v6 containing transcripts among the different primary samples (Online Supplementary Figure S5A). Interestingly, in OCIAML3 CD44v6 cells, co-immunoprecipitated with CD49d, with a slight pull down increase when cells were preincubated with HA (Online Supplementary Figure S5B). In conclusion, our data demonstrate that HA/CD44 binding induces CD49d cluster formation in AML, but not normal CD34 progenitor cells, without changing the conformation of the VLA-4 heterodimer.

\section{Src family kinase inhibition and midostaurin treatment interfere with the CD44-VLA-4 activation axis}

Src family kinases (SFK) are important downstream molecules of $\mathrm{HA} / \mathrm{CD} 44^{23}$ and likely candidates for integrin activation. ${ }^{24}$ To confirm Src and PIBK activation upon HA treatment, we analyzed Src and Akt phosphorylation by western blot in native, control and shCD44-transduced OCIAML3 cells (Online Supplementary Figure S6A). Remarkably, treating cells with the pan-SFK inhibitor PP2 abrogated the formation of HA-induced CD49d clusters on the surface of OCI-AML3 cells (Figure 4Ai) and six different AML patients' samples (Figure 4Aii $+\mathrm{Ci}$ ), providing evidence that CD 49d clustering was Src family-dependent. To start from broad but therapeutically relevant kinase inhibition, we used the multikinase inhibitor midostaurin, approved for the treatment of FLT3-mutated AML. We found that midostaurin is highly potent in antagonizing HA-induced CD49d cluster formation of OCI-AML3 cells (Figure 4Bi) 
and six different AML patients' samples independently of their FLT3 mutation status (FLT3 wild-type [n=3], FLT3-ITD $[\mathrm{n}=3]$ ) (Figure 4Bii + Cii).

Additional experiments, using the MEK inhibitor cobimetinib and the PI3Kס inhibitor idelalisib, further suggested that PI3K, but not MAPK pathways are involved in CD44triggered inside-out CD49d cluster formation (Online Supplementary Figure S6B). We next confirmed that PP2, midostaurin and idelalisib treatment not only inhibited cluster formation, but also reduced the binding of primary
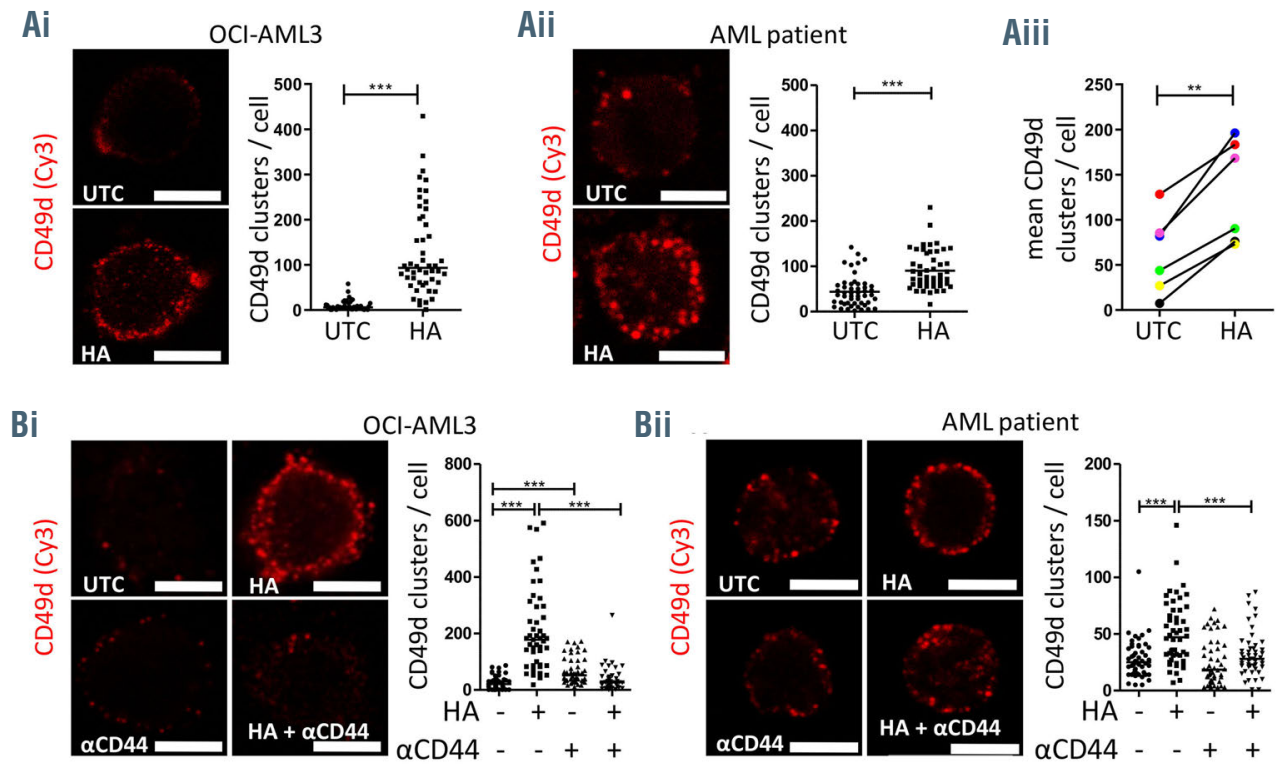

Biii

Ci
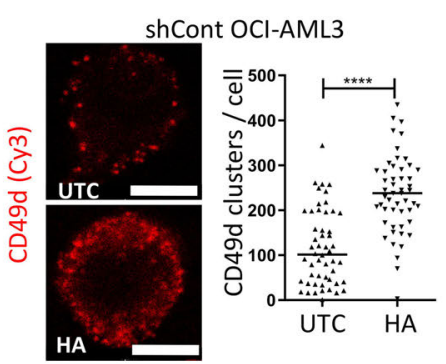

Cii

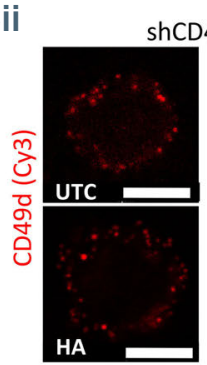

shCD44 OCI-AML3

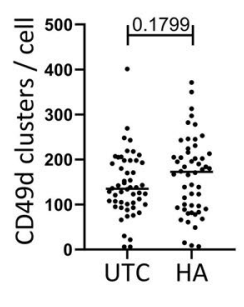

Eii

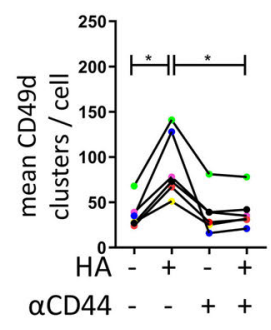

Dii

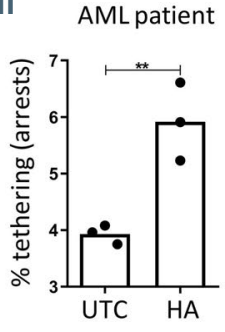

$\mathrm{Ei}$

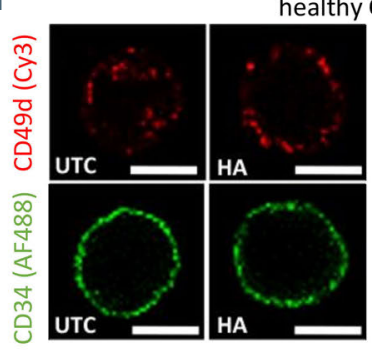

healthy $\mathrm{CD} 34^{+}$cells

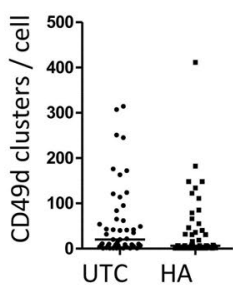

Di

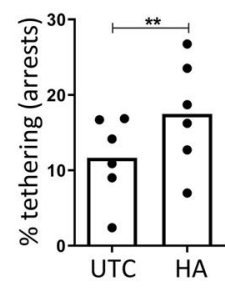


AML cells (Figure 4D) and OCI-AML3 cells (Online Supplementary Figure S6C) to VCAM-1 under shear flow conditions. Collectively, our findings point to a Src familyand PIBK-dependent signaling pathway that is initiated upon HA/CD44 engagement, leading to CD49d cluster formation.

The hyaluronic acid-induced VLA-4/VCAM-1 interaction promotes an acute myeloid leukemia cell-stromal cell interaction leading to Akt, MAPK and NF- $K B$ pathway activation

To further identify the impact of the CD44-mediated VLA-4 activation on pathophysiologically relevant processes in the BM microenvironment, we used a static adhesion assay combined with microscopy of AML cells on a stromal cell layer. Untreated or HA-pretreated OCI-AML3 cells or primary AML cells from four different patients were co-cultured with stromal cells for $30 \mathrm{~min}$. After extensive washing, cell nuclei were visualized via DAPI staining. We found that HA-pretreated cells had a much higher ability to adhere firmly to stromal cells. We confirmed that this adhesion was dependent on the HA-induced interaction of VLA4 expressed by the AML cells and the VCAM-1 expressed by the stromal cell, as additional pretreatment with the $\alpha C D 44$ antibody as well as pretreatment with the $\alpha \mathrm{CD} 49 \mathrm{~d}$ antibody inhibited the HA-induced adhesion of OCI-AML3 cells on stromal cells (Figure 5A, B). Additional controls using CD44 knockdown and control transduced OCIAML3 cells (Online Supplementary Figure S7A) as well as native OCI-AML3 on $\alpha$ VCAM-1-antibody-treated stromal
Ai

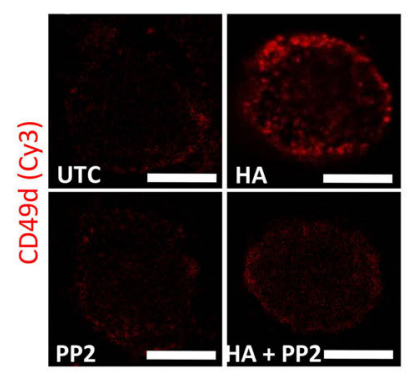

OCI-AML3

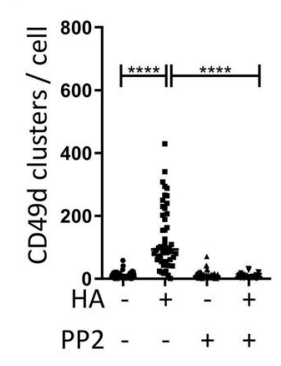

Aii

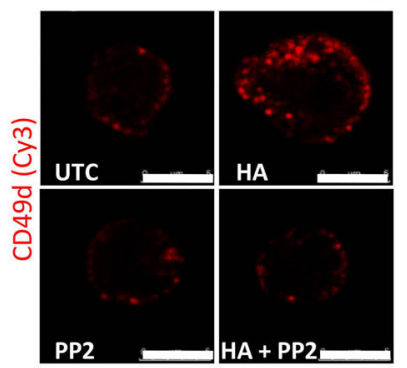

AML patient

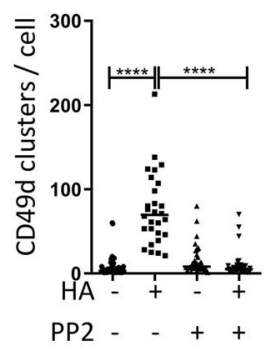

Bi

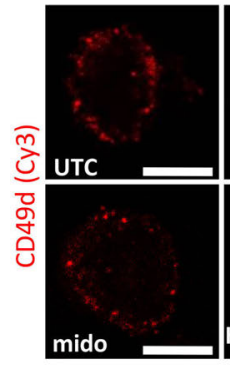

OCI-AML3

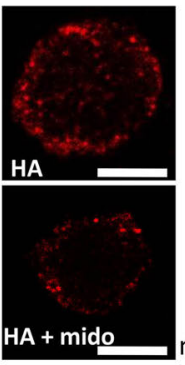

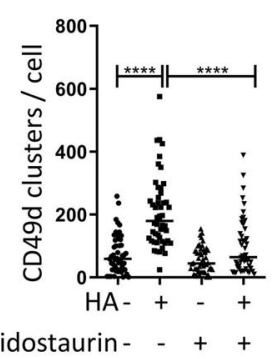

Bii

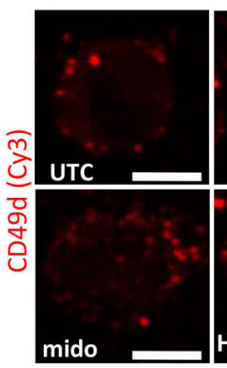

AML patient
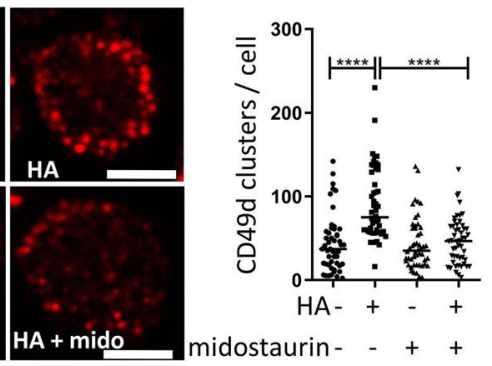

AML patients

Ci

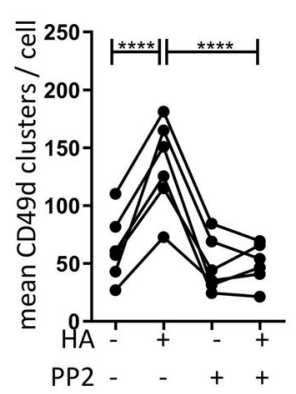

Cii

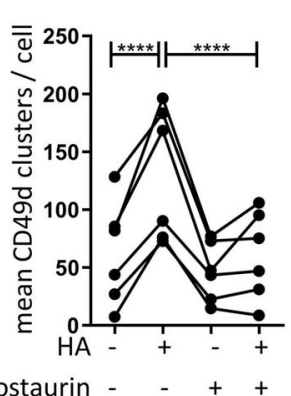

Di

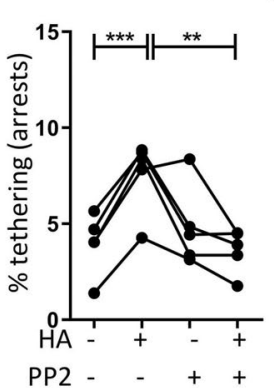

AML patients

Dii

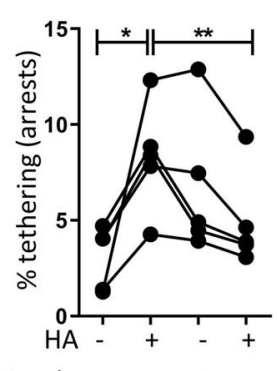

Figure 4. Src family kinase inhibition and midostaurin treatment of acute myeloid leukemia cells inhibit hyaluronic acid-induced cluster formation. (A) Confocal images of OCI-AML3 (i) or primary acute myeloid leukemia (AML) cells from bone marrow (BM) aspirates (ii) that were or were not pretreated with $\mathrm{HA}$ and/or the Src family kinase (SFK) inhibitor PP2. Cells were stained with $\alpha \mathrm{CD} 49 \mathrm{~d}$ (red) monoclonal antibody (clone AHP1225). For OCl-AML3, one representative experiment of three is shown; for primary samples, one representative experiment of six is shown ( $n=50$ cells). (B) Confocal images of OCl-AML3 (i) or primary AML cells from BM aspirates (ii). Cells were pretreated or not with HA and/or the multikinase inhibitor midostaurin. Cells were stained with $\alpha \mathrm{CD} 49 \mathrm{~d}$ (red) monoclonal antibody. For OCl-AML3, one representative experiment of three is shown; for primary samples, one representative experiment of six is shown ( $n=50$ cells). (C) Mean numbers of CD49d clusters per cell were compared from six different patients' samples with/without HA treatment and with/without PP2 treatment (i) or with/without midostaurin (ii). (D) Primary AML cells from five different patients with/without HA treatment and with/without PP2 treatment (i) or with/without midostaurin (ii) were subjected to shear flow analyses over VCAM-1. Oneway analyses of variance with multiple comparisons were used. Bars, $5 \mu \mathrm{m}$. $* P<0.05 ; * * P<0.01 ; * * \star P<0.001 ; * * * * P<0.0001$; ns: not significant. 
cells confirmed the specificity of the HA-CD44 interactions in triggering adhesion on VCAM-1 expressed by stromal cells (Online Supplementary Figure S7B).

We next investigated downstream signaling of this VLA4/VCAM-1 interaction in AML cells by western blotting and quantified phosphorylation levels of previously shown signaling molecules that are important for AML cell survival, namely Akt, ERK, IкB and mTOR ${ }^{1}$ Primary cells from five different AML patients were treated with HA and/or with VCAM-1-coated beads, where indicated. In contrast to brief HA treatment, VCAM-1-coated beads alone were sufficient to increase phosphorylation of Akt, ERK, IкB and mTOR in primary AML cells (Figure 6A, B). This can be attributed to the experimental three-dimensional nature of this system, which allows a lot more cells to bind to the VCAM-1-coated beads than immobilized VCAM-1 used for microscopy (Online Supplementary Figure S8A). In line with this, VCAM-1 also triggered phosphorylation of ERK, $\mathrm{IkB}$, FAK and paxillin (Pax) in OCI-AML3 cells (Online Supplementary Figure S8B).

In light of the key role of active Akt, MAPK, and NF- $\mathrm{B} B$ signaling in leukocyte survival, we next tested the protec- tive effect of the CD44-VLA-4-dependent cell adhesion in the context of chemotherapy. We found that OCI-AML3 cells adherent to a co-immobilized substrate of HA and VCAM-1 underwent less doxorubicin-induced apoptosis than cells lacking such a substrate. CD49d expression was mandatory for the protective effect as CD49d knockdown cells were not protected by HANCAM-1 (Figure 6C). The importance of CD49d in leukemic progression was also confirmed by long-term in vivo engraftment experiments in NSGS mice. AML progression was decelerated upon engraftment of CD49d knockdown (shCD49d) OCI-AML3 cells as compared to engraftment of control cells (shCont) (Figure 6D). In a xenotransplant model anti-CD49d antibody treatment altered the organ-specific localization of engrafted MOLM-13 cells, but did not significantly prolong the overall survival of mice undergoing cytarabine (AraC) treatment (Online Supplementary Figure S9). At this point we were not successful in establishing a model for testing standard induction therapy (combined AraC-doxorubicin) and anti-CD49d treatment in immunodeficient mice, as doxorubicin requires careful further dosing studies to avoid severe toxicities.
A

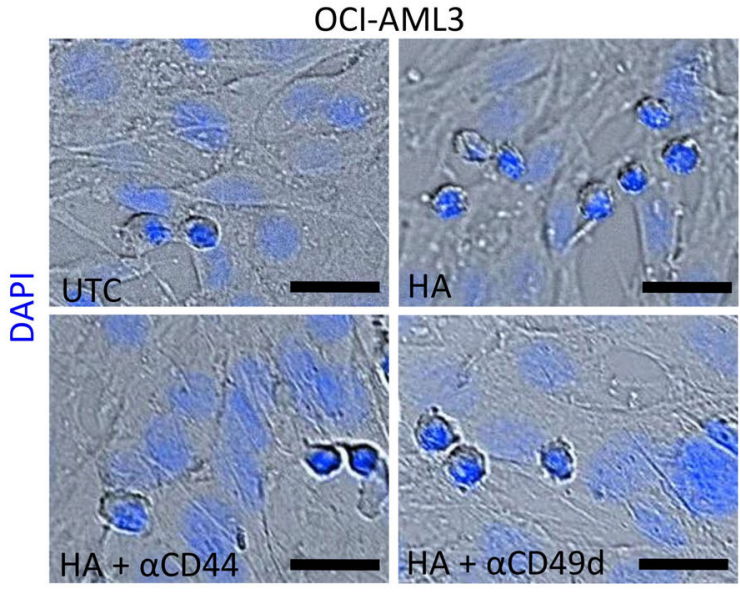

B

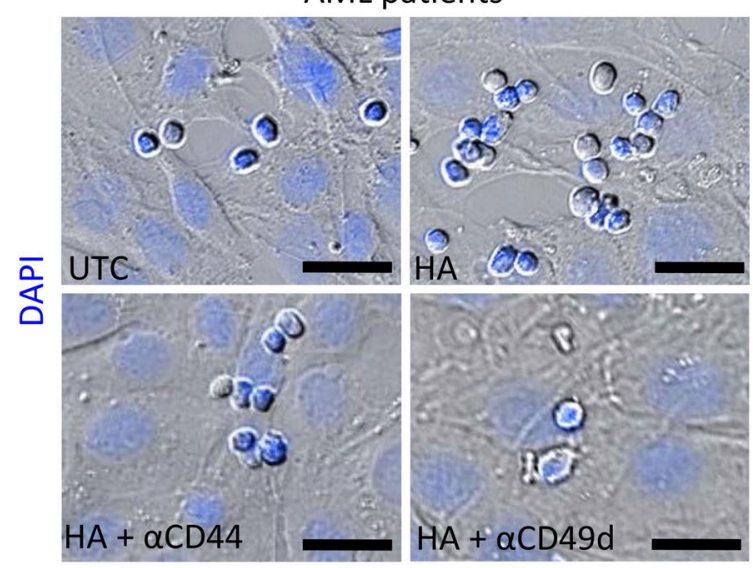

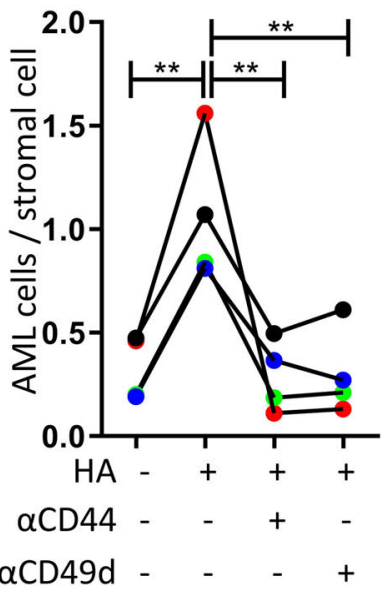

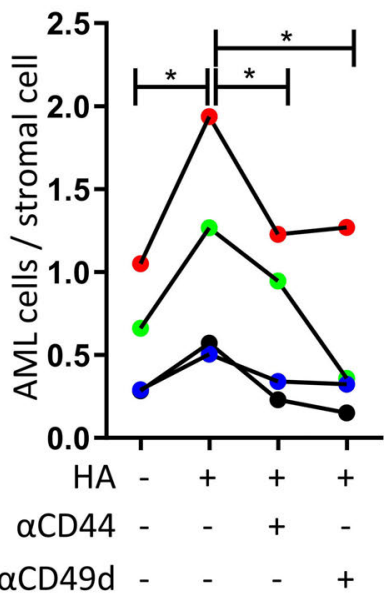

Figure 5. Hyaluronic acid treatment leads to strong interaction between acute myeloid leukemia cells and stromal cells. OCI-AML3 cells ( $\mathrm{n}=4$ ) $(\mathrm{A})$ or primary cells from bone marrow (BM) aspirates from four different patients with acute myeloid leukemia (AML) (B) were pretreated or not with $\mathrm{HA}$ and/or $\alpha \mathrm{CD} 44$ (clone 515) or $\alpha \mathrm{CD} 49 \mathrm{~d}$ (clone HP2/1) and allowed to adhere to M2 stromal cells for $30 \mathrm{~min}$. The number of AML cells that bound to the stromal cells was counted on bright field images with additional DAPI staining by fluorescence microscopy. One-way analyses of variance with multiple comparisons were used. Images were taken at $20 x$ magnification. Bars, $20 \mu \mathrm{m}$. ${ }^{*} P<0.05 ; * * P<0.01$. 
In conclusion, we demonstrate that HA-induced VLA-4 cluster formation is critical for direct cell-cell contact of human AML cells with stromal cells, thereby contributing to supportive signaling pathways in AML cells (Figure 7).

\section{Discussion}

The BM microenvironment plays a decisive role in the evolution and persistence of AML. ${ }^{1}$ Adhesive processes are mandatory to signal perception and leukemia cell-microenvironment communication by facilitating the retention of the tumor cells to protective cues. Moreover, CD44 has been reported to be a marker of primary human AML cancer stem cells and its blockade revealed a potential for differentiation in human AML cell lines. ${ }^{3,25,26}$ Here, we identi- fied a novel non-classical HA/CD44-triggered way of inside-out activation of the integrin VLA-4, leading to VLA4 cluster formation and increased adhesive strength on VCAM-1, important for the direct interaction of AML cells with supportive stromal cells.

In short-term adoptive transfers of human primary AML cells to immunodeficient mice, we observed that CD44 had a key function in rapid tumor cell homing to BM and spleen, reflecting the biology of normal cellular counterparts as well as malignant cells, e.g. chronic myeloid leukemia-initiating cells. ${ }^{27,28}$ However, BM engraftment of malignant cells is dependent not only on homing events but even more on retention of the cells in distinct supportive zones of this organ. ${ }^{1}$ The VLA-4 integrin is known for being key for the retention of progenitor cells in BM. ${ }^{29}$ The strength of binding of the integrin to its ligand VCAM-1,
A

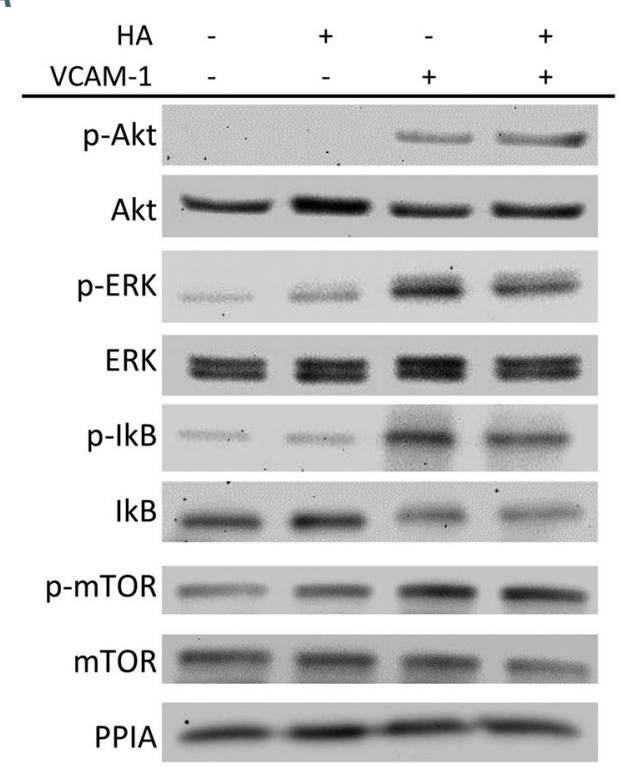

C

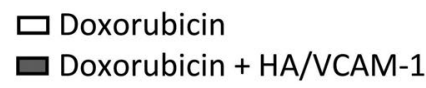

D
B
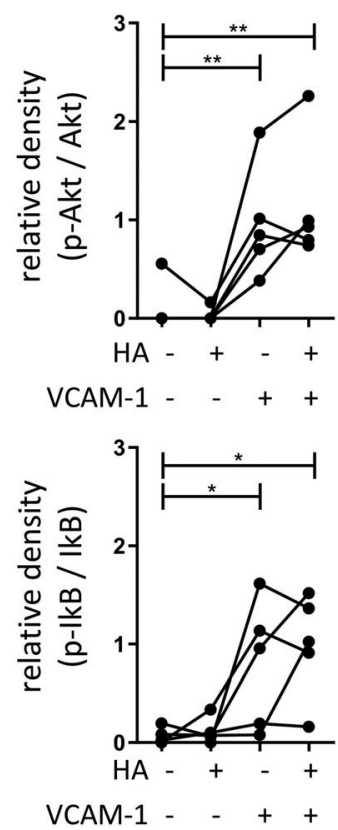
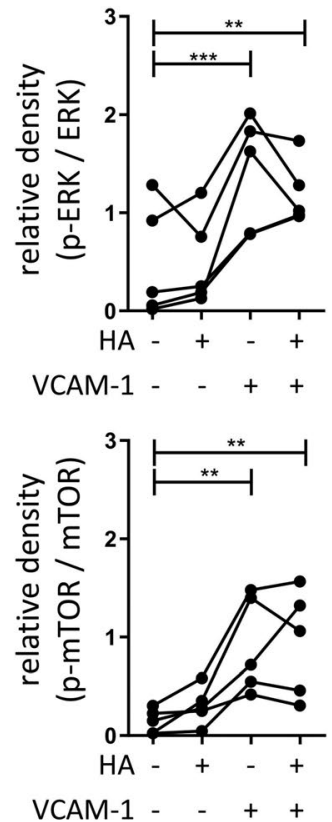
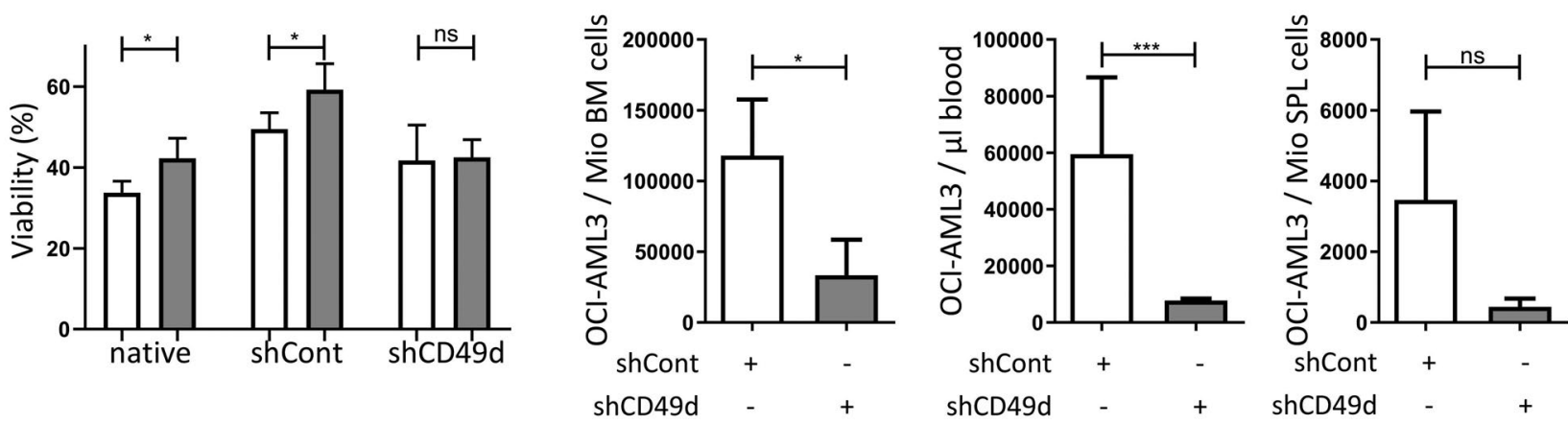

Figure 6. VLA-4 engagement triggers the phosphorylation of Akt, ERK, IKB and mTOR and contributes to acute myeloid leukemia progression. (A) Protein lysates of primary acute myeloid leukemia (AML) cells from bone marrow (BM) aspirates were treated or not with hyaluronic acid (HA) and/or VCAM-1-coated beads and tested for their ERK, phospho-ERK, Akt, phospho-Akt, IkB $\alpha$, phospho-IkB $\alpha$, mTOR and phospho-mTOR content by western blot. One representative experiment of five is shown. (B) Five independent experiments with five different AML patients' samples were quantified. Expression intensities were quantified with ImageJ software and phosphorylation was normalized to total protein content. One-way analyses of variance with multiple comparisons were used. (C) Apoptosis of native, shCont or shCD49d OCIAML3 cells was induced with $0.5 \mu \mathrm{M}$ of doxorubicin; additionally, cells were treated with immobilized HA and VCAM-1, where indicated. Cell viability was determined using trypan blue. Four replicates of one representative experiment of two independent experiments are shown. (D) Number of shCont or shCD49d OCI-AML3 cells in BM, blood, and spleen (SPL) of NSG mice, 28 days after intravenous injection ( $\mathrm{n}=7$ per group). ${ }^{*} P<0.05 ; * * P<0.01 ; * * * P<0.001$; ns: not significant. 
which is presented by stromal cells, is thereby regulated by signaling cascades inducing increased affinity due to conformational changes of the integrin, the so-called inside-out signaling. ${ }^{30}$ In contrast to the well-described, classical, chemokine-induced VLA-4 inside-out activation by conformational affinity alterations, less is known about chemokine-independent alternative integrin activation. ${ }^{14,31}$ We have previously observed that in B-cell malignancies, signals via the B-cell receptor can induce changes not only in the affinity but also the avidity of the VLA-4 receptor. ${ }^{11}$ Here, we identified an AML-specific HA/CD44-mediated VLA-4 activation via integrin cluster formation without obvious conformational modulation, further promoting strong VLA-4/VCAM-1 binding. This chemokine bypass from CD44 towards VLA-4 is somewhat reminiscent of the previously observed E-selectin/HCELL-VLA-4 interaction in mesenchymal stem cells, ${ }^{32}$ but it clearly differs in the receptor-ligand couple (HA-CD44) and is observed for the first time in a leukocyte. Nevertheless, the reminiscence may point to a more general mechanism and is also interesting in light of the relevant role of E-selectin in AML and other hematologic malignancies. ${ }^{33-38}$ Notably, we did not observe CD44-VLA-4 inside-out activation in normal CD34+ mobilized progenitors, suggesting this is a transformation-related and tumor-acquired feature for increasing integrin-mediated retention of AML cells.

SFK are crucial downstream signaling molecules of CD44 in hematopoietic cells of healthy and sick individuals. ${ }^{39.41}$ They can contribute to enrichment of CD44/ $\beta 1$ integrin complexes in lipid rafts ${ }^{42}$ and also function immediately downstream of integrins, in concert with focal adhesion kinases. ${ }^{43}$ Employing the SFK inhibitor PP2, we identified SFK within the CD44-mediated VLA-4 inside-out activation cascade, and propose that a further stabilization of
VLA-4 clusters involves Src-FAK signaling. This could have therapeutic relevance as PP2 administration was reported to attenuate progression of a FLT3-mutated AML model. ${ }^{44}$ However, in the light of the complexity of the Src kinase family, the particular kinase responsible for the HA/CD44mediated inside-out signaling needs to be elucidated by a genetic screening approach.

We investigated the therapeutically relevant drug midostaurin, which is approved for treatment of FLT3mutant $\mathrm{AML},{ }^{45}$ and currently under clinical investigations in non-FLT3-mutated AML cases (NCT03512197). Midostaurin is a broad multikinase inhibitor, and more selective inhibitors, such as gilteritinib and quizartinib for FLT3 and dasatinib for Src kinases, recently entered the clinical stage. ${ }^{46-48}$ Notably, kinase signals via FLT3-ITD can increase the affinity of VLA-4 to soluble VCAM-1. ${ }^{49}$ Thus, the here reported CD44-dependent mechanism of VLA-4 activation may be an alternative pathway used by FLT3 wild-type AML cells to increase their adhesion to protective stromal cells. As FLT3 mutation status is an important prognostic marker in AML, it is interesting that the observed CD44/VLA-4 crosstalk was independent from the patients' FLT3 mutation status, suggesting involvement of alternative compensatory kinases.

Further downstream of SFK, we supposed PI3K to mediate signaling ${ }^{50.52}$ and indeed observed diminished HAinduced CD49d cluster formation in the presence of the PI3K $\delta$ inhibitor idelalisib. PI3K has been described to promote human AML survival and BM stromal cell-mediated protection, ${ }^{53}$ giving a rationale to investigate $\mathrm{PI} 3 \mathrm{~K}$ inhibitors further in AML. As another functional consequence, the VLA-4-mediated AML adhesion triggered activation of Akt, MAPK, mTOR and NF-кB pathways, which are known important mediators of AML survival. ${ }^{53,54}$ However, in a first

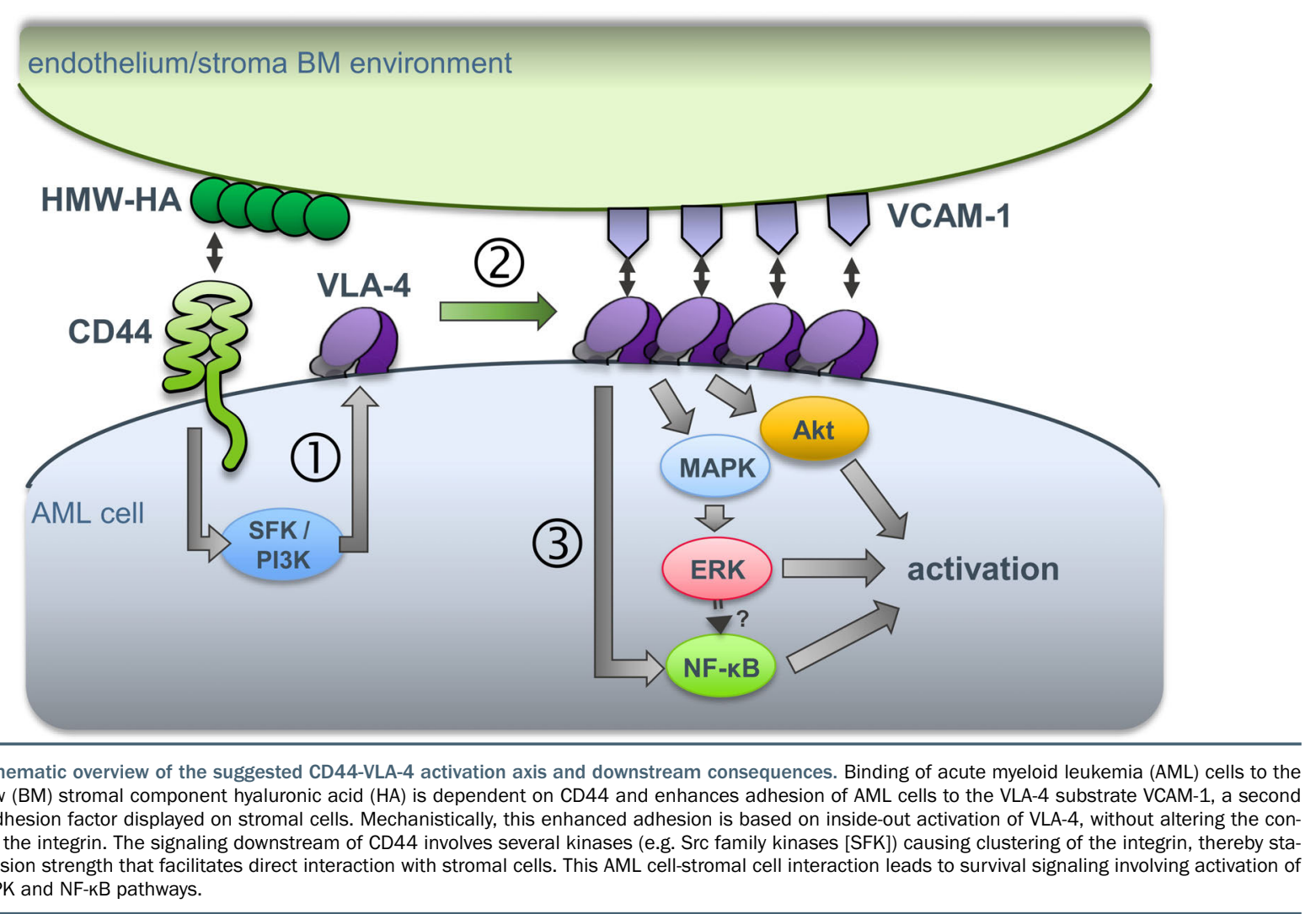

Figure 7. Schematic overview of the suggested CD44-VLA-4 activation axis and downstream consequences. Binding of acute myeloid leukemia (AML) cells to the bone marrow (BM) stromal component hyaluronic acid (HA) is dependent on CD44 and enhances adhesion of AML cells to the VLA-4 substrate VCAM-1, a second important adhesion factor displayed on stromal cells. Mechanistically, this enhanced adhesion is based on inside-out activation of VLA-4, without altering the conformation of the integrin. The signaling downstream of CD44 involves several kinases (e.g. Src family kinases [SFK]) causing clustering of the integrin, thereby stabilizing adhesion strength that facilitates direct interaction with stromal cells. This AML cell-stromal cell interaction leads to survival signaling involving activation of the Akt, MAPK and NF-kB pathways. 
xenograft model we could not establish a treatment regime of combined VLA-4 inhibition and induction chemotherapy with a survival benefit for the mice. While this argues for kinase inhibition as the preferential cytarabine combination partner, it does not exclude a role of VLA-4 inhibition in other treatment schedules or at other disease points, e.g. during graft-versus-host management.

Taking all our data together, we suggest that HA binding to CD44 triggers a signaling axis via SFK and PI3K to rapidly trigger VLA-4 avidity and hence support the retention of AML cells in their preferential niches (Figure 7). Compensatory survival mechanisms of malignant cells still comprise a major challenge in current AML therapy which may be tackled by the use of combinatorial therapies, administering kinase inhibitors that may help to interfere with cellular position as well as growth signaling accompanied by drugs inducing apoptosis, as a step forward in improving current treatment modalities.

\section{Disclosures}

No conflicts of interest to disclose.

\section{Contributions}

JCG and TNH conceived and designed the study and wrote the manuscript. JCG, EB, XY,JML, $A R, A C$ and $D N$ developed the methodology. JCG, EB, XY, JML, JPH, GA, TR, AS, ES, TH, AH, ST, SP, AR, MA, AC and DN acquired data. JCG, EB, XY, JML, GA, TR, AS, AH, AC, DN, DFL; VO-R,
$R G$ and TNH analyzed and interpreted the data. JCG, EB, $X Y, J M L$, JPH, GA, ST, TR, AS, ES, VD-O, AR, AH, NZ, $A C, F A, D N$ and $D F L$ reviewed and/or revised the manuscript. RG, LP, DN, DFL, VO-R. FA and TNH provided administrative, technical, or material support. TNH supervised the study.

\section{Acknowledgments}

We thank all patients for their participation in this study. We also thank the staff from Charles River Research Services Germany GmbH for excellent technical support. We thank Christoph Ratswohl for helpful revision of the manuscript and Alexandra Hödmoser for support with handling the mice.

\section{Funding}

This work was supported by the SCRI-LIMCR GmbH, the province of Salzburg as support to the Cancer Cluster Salzburg work package 2, the Austrian Science Fund (FWF) 25015-B13 (to TNH), the PhD program Immunity in Cancer and Allergy (W1213, Austrian Science Fund) (to TNH, FA and RG), the Paracelsus Medical University PMU-FFF E-15/22/114-HAR (to TNH), the Wilhelm-Seiter Stiftung Freiburg (to TNH), the Deutsche Forschungsgemeinschaft (DFG, German Research Foundation) - 419090910 (to TNH) and the Swiss National Science Foundation (169936 \& 189144) (to DFL). This work was also supported by the National Institutes of Health (USA) grant: UNM Comprehensive Cancer Center CCSG P3O CA118100 (to AC).

\section{References}

1. Zhou HS, Carter BZ, Andreeff M. Bone marrow niche-mediated survival of leukemia stem cells in acute myeloid leukemia: yin and yang. Cancer Biol Med. 2016;13(2):248259.

2. Naor D, Nedvetzki S, Golan I, Melnik L, Faitelson Y. CD44 in cancer. Crit Rev Clin Lab Sci. 2002;39(6):527-579.

3. Jin L, Hope KJ, Zhai Q, Smadja-Joffe F, Dick JE. Targeting of CD44 eradicates human acute myeloid leukemic stem cells. Nat Med. 2006;12(10):1167-1174.

4. Alon R, Dustin ML. Force as a facilitator of integrin conformational changes during leukocyte arrest on blood vessels and antigen-presenting cells. Immunity. 2007;26(1): 17-27.

5. Dustin ML, Bivona TG, Philips MR. Membranes as messengers in $\mathrm{T}$ cell adhesion signaling. Nat Immunol. 2004;5(4):363372.

6. Lundell BI, McCarthy JB, Kovach NL, Verfaillie CM. Activation of beta1 integrins on CML progenitors reveals cooperation between beta1 integrins and CD44 in the regulation of adhesion and proliferation. Leukemia. 1997;11(6):822-829.

7. Verfaillie CM, Benis A, Iida J, McGlave PB, McCarthy JB. Adhesion of committed human hematopoietic progenitors to synthetic peptides from the C-terminal heparinbinding domain of fibronectin: cooperation between the integrin alpha 4 beta 1 and the CD44 adhesion receptor. Blood. 1994;84(6): 1802-1811.

8. Singh V, Erb U, Zoller M. Cooperativity of CD44 and CD49d in leukemia cell homing, migration, and survival offers a means for therapeutic attack. J Immunol. 2013;191(10): 5304-5316.

9. Brachtl G, Sahakyan K, Denk U et al.
Differential bone marrow homing capacity of VLA-4 and CD38 high expressing chronic lymphocytic leukemia cells. PLoS One. 2011;6(8):e23758

10. Gutjahr JC, Szenes E, Tschech L, et al. Microenvironment-induced CD44v6 promotes early disease progression in chronic lymphocytic leukemia. Blood. 2018;131(12): 1337-1349.

11. Tissino E, Benedetti D, Herman SEM, et al. Functional and clinical relevance of VLA-4 (CD49d/CD29) in ibrutinib-treated chronic lymphocytic leukemia. J Exp Med. 2018;215(2): 681-697

12. Laufer JM, Lyck R, Legler DF. ZAP70 expression enhances chemokine-driven chronic lymphocytic leukemia cell migration and arrest by valency regulation of integrins. FASEB J. 2018;32(9):4824-4835.

13. Lacombe F, Durrieu F, Briais A, et al. Flow cytometry CD45 gating for immunophenotyping of acute myeloid leukemia. Leukemia. 1997;11(11):1878-1886.

14. Lapidot T, Dar A, Kollet O. How do stem cells find their way home? Blood. 2005;106 (6):1901-1910.

15. Ganghammer S, Hutterer E, Hinterseer E, et al. CXCL12-induced VLA-4 activation is impaired in trisomy 12 chronic lymphocytic leukemia cells: a role for CCL21. Oncotarget. 2015;6(14):12048-12060.

16. Tavianatou AG, Caon I, Franchi M, Piperigkou Z, Galesso D, Karamanos NK. Hyaluronan: molecular size-dependent signaling and biological functions in inflammation and cancer. FEBS J. 2019;286(15):28832908.

17. Peled A, Kollet O, Ponomaryov T, et al. The chemokine SDF-1 activates the integrins LFA-1, VLA-4, and VLA-5 on immature human CD34(+) cells: role in transendothelial/stromal migration and engraftment of
NOD/SCID mice. Blood. 2000;95(11):32893296

18. Chigaev A, Zwartz GJ, Buranda T, Edwards BS, Prossnitz ER, Sklar LA. Conformational regulation of alpha 4 beta 1 -integrin affinity by reducing agents. "Inside-out" signaling is independent of and additive to reductionregulated integrin activation. J Biol Chem. 2004;279(31):32435-32443.

19. Kim M, Carman CV, Yang W, Salas A Springer TA. The primacy of affinity over clustering in regulation of adhesiveness of the integrin \{alpha\}L\{beta\}2. J Cell Biol. 2004;167(6):1241-1253.

20. Chigaev A, Waller A, Amit O, Halip L, Bologa CG, Sklar LA. Real-time analysis of conformation-sensitive antibody binding provides new insights into integrin conformational regulation. J Biol Chem. 2009;284 (21):14337-14346

21. Alon R, Feigelson SW, Manevich E, et al. Alpha4beta1-dependent adhesion strengthening under mechanical strain is regulated by paxillin association with the alpha4-cytoplasmic domain. J Cell Biol. 2005;171(6): 1073-1084.

22. Legras S, Gunthert U, Stauder R, et al. A strong expression of CD44-6v correlates with shorter survival of patients with acute myeloid leukemia. Blood. 1998;91(9):34013413.

23. Ponta H, Sherman L, Herrlich PA. CD44: from adhesion molecules to signalling regulators. Nat Rev Mol Cell Biol. 2003;4(1):33-45.

24. Bouaouina M, Blouin E, HalbwachsMecarelli L, Lesavre P, Rieu P. TNF-induced beta 2 integrin activation involves Src kinases and a redox-regulated activation of p38 MAPK. J Immunol. 2004;173(2):1313-1320.

25. Gadhoum SZ, Madhoun NY, Abuelela AF Merzaban JS. Anti-CD44 antibodies inhibit both mTORC1 and mTORC2: a new 
rationale supporting CD44-induced AML differentiation therapy. Leukemia. 2016;30 (12):2397-2401.

26. Charrad RS, Gadhoum Z, Oi JY, et al. Effects of anti-CD44 monoclonal antibodies on differentiation and apoptosis of human myeloid leukemia cell lines. Blood. 2002;99(1):290-299.

27. Avigdor A, Goichberg P, Shivtiel S, et al. CD44 and hyaluronic acid cooperate with SDF-1 in the trafficking of human CD34+ stem/progenitor cells to bone marrow. Blood. 2004;103(8):2981-2989.

28. Krause DS, Lazarides K, von Andrian UH, Van Etten RA. Requirement for CD44 in homing and engraftment of BCR-ABLexpressing leukemic stem cells. Nat Med. 2006;12(10):1175-1180.

29. Bendall LJ, Kortlepel K, Gottlieb DJ. Human acute myeloid leukemia cells bind to bone marrow stroma via a combination of beta-1 and beta-2 integrin mechanisms. Blood. 1993;82(10):3125-3132.

30. Chigaev A, Blenc AM, Braaten JV, et al. Real time analysis of the affinity regulation of alpha 4-integrin. The physiologically activated receptor is intermediate in affinity between resting and $\mathrm{Mn}(2+)$ or antibody activation. J Biol Chem. 2001;276(52):4867048678.

31. Laufer JM, Legler DF. Beyond migrationChemokines in lymphocyte priming, differentiation, and modulating effector functions. J Leukoc Biol. 2018;104(2):301-312.

32. Thankamony SP, Sackstein R. Enforced hematopoietic cell E- and L-selectin ligand (HCELL) expression primes transendothelial migration of human mesenchymal stem cells. Proc Natl Acad Sci U S A. 2011;108 (6):2258-2263.

33. Chien S, Haq SU, Pawlus M, et al. Adhesion of acute myeloid leukemia blasts to Eselectin in the vascular niche enhances their survival by mechanisms such as Wnt activation. Blood. 2013;122(21):61.

34. Rashidi A, Uy GL. Targeting the microenvironment in acute myeloid leukemia. Curr Hematol Malig Rep. 2015;10(2):126-131.

35. Morita K, Tokushige C, Maeda S, et al. RUNX transcription factors potentially con- trol E-selectin expression in the bone marrow vascular niche in mice. Blood Adv. 2018;2(5):509-515.

36. Barbier V, Erbani J, Fiveash C, et al Endothelial E-selectin inhibition improves acute myeloid leukaemia therapy by disrupting vascular niche-mediated chemoresistance. Nat Commun. 2020;11(1):2042.

37. Krause DS, Lazarides K, Lewis JB, et al. Selectins and their ligands are required for homing and engraftment of BCR-ABL1+ leukemic stem cells in the bone marrow niche. Blood. 2014;123(9):1361-1371.

38. Godavarthy PS, Kumar R, Herkt SC, et al. The vascular bone marrow niche influences outcome in chronic myeloid leukemia via the E-selectin - SCL/TAL1 - CD44 axis. Haematologica. 2020;105(1):136-147.

39. Malfuson JV, Boutin L, Clay D, et al. SP/drug efflux functionality of hematopoietic progenitors is controlled by mesenchymal niche through VLA-4/CD44 axis. Leukemia. 2014;28(4):853-864

40. Yago T, Shao B, Miner JJ, et al. E-selectin engages PSGL-1 and CD44 through a common signaling pathway to induce integrin alphaLbeta2-mediated slow leukocyte rolling. Blood. 2010;116(3):485-494.

41. Ilangumaran S, Briol A, Hoessli DC. CD44 selectively associates with active Src family protein tyrosine kinases Lck and Fyn in glycosphingolipid-rich plasma membrane domains of human peripheral blood lymphocytes. Blood. 1998;91(10):3901-3908.

42. Lee JL, Wang MJ, Sudhir PR, Chen JY. CD44 engagement promotes matrix-derived survival through the CD44-SRC-integrin axis in lipid rafts. Mol Cell Biol. 2008;28(18):57105723.

43. Huveneers S, Danen EH. Adhesion signaling - crosstalk between integrins, Src and Rho. J Cell Sci. 2009;122(Pt 8):1059-1069.

44. Okamoto M, Hayakawa F, Miyata Y, et al Lyn is an important component of the signal transduction pathway specific to FLT3/ITD and can be a therapeutic target in the treatment of AML with FLT3/ITD. Leukemia. 2007;21(3):403-410.

45. Levis M. Midostaurin approved for FLT3 mutated AML. Blood. 2017;129(26):3403-
3406.

46. Cortes JE, Tallman MS, Schiller GJ, et al Phase $2 b$ study of two dosing regimens of quizartinib monotherapy in FLT3-ITD mutated, relapsed or refractory AML. Blood. 2018;132(6):598-607.

47. Perl AE, Altman JK, Cortes J, et al. Selective inhibition of FLT3 by gilteritinib in relapsed or refractory acute myeloid leukaemia: a multicentre, first-in-human, open-label, phase 1-2 study. Lancet Oncol. 2017;18 (8):1061-1075

48. Paschka P, Schlenk RF, Weber D, et al Adding dasatinib to intensive treatment in core-binding factor acute myeloid leukemiaresults of the AMLSG 11-08 trial. Leukemia. 2018;32(7):1621-1630

49. Katsumi A, Kiyoi H, Abe A, et al. FLT3/ ITD regulates leukaemia cell adhesion through alpha4beta1 integrin and Pyk2 signalling. Eur J Haematol. 2011;86(3):191-198.

50. Lu Y, Yu Q, Liu JH, et al. Src family proteintyrosine kinases alter the function of PTEN to regulate phosphatidylinositol 3 kinase/AKT cascades. J Biol Chem. 2003;278(41):40057-40066.

51. Roversi FM, Pericole FV, Machado-Neto JA, et al. Hematopoietic cell kinase (HCK) is a potential therapeutic target for dysplastic and leukemic cells due to integration of erythropoietin/PI3K pathway and regulation of erythropoiesis: HCK in erythropoietin/PI3K pathway. Biochim Biophys Acta. 2017;1863 (2):450-461.

52. Zhu QS, Xia L, Mills GB, Lowell CA, Touw IP, Corey SJ. G-CSF induced reactive oxygen species involves Lyn-PI3-kinase-Akt and contributes to myeloid cell growth. Blood. 2006;107(5):1847-1856.

53. Pillinger G, Loughran NV, Piddock RE, et al. Targeting PI3Kdelta and PI3Kgamma sig nalling disrupts human AML survival and bone marrow stromal cell mediated protection. Oncotarget. 2016;7(26):39784-39795.

54. Su Y, Li X, Ma J, et al. Targeting PIBK, mTOR, ERK, and Bcl-2 signaling network shows superior antileukemic activity against AML ex vivo. Biochem Pharmacol. 2018; 148:13-26. 